\section{Commentary: Small can be beautiful, in the right hands}

\author{
Lucius K. F. Lee, MB, ChB(CUHK), and \\ Michael K. Y. Hsin, FRCS, CTh
}

Matching appropriately sized donor lungs for patients of small stature who are listed for lung transplant (LTx) is challenging, which results in longer waitlist time and increased morbidity and mortality. This may be addressed by surgical down-sizing of the donor lung. Nonanatomical wedge resection, usually to the right middle lobe or lingula, can achieve a $10 \%$ to $15 \%$ down-sizing. ${ }^{1}$ When size discrepancy is significant, cadaveric lobar lung transplantation (LLTx) may be considered. First reported by Bisson in 1994, cadaveric LLTx remains infrequently performed, and published reports are limited. ${ }^{2}$

In this issue of the Journal, the Toronto group reported one of the largest published series of cadaveric LLTxbetween 2000 and 2017, they performed 75 LLTx procdures. ${ }^{3}$ Pulmonary fibrosis was the most common diagnosis, and similar to previous reports, recipients of LLTx were more likely to be rapidly deteriorating and required bridging by mechanical ventilation or extracorporeal life support. ${ }^{4-7}$

When compared with standard LTx, their recipients of LLTx were more likely to have postoperative primary graft dysfunction grade 3 or extracorporeal membrane oxygenation and longer intensive care unit and hospital length of stay. Both 30- and 90-day mortality was greater in the LLTx group. In a subanalysis, in the modern era, the LLTx group 90-day mortality was no different from the standard LTx. Survival at 1, 3, and 5 years, and the development of chronic lung allograft dysfunction, was no different between LLTx and standard LTx.

From the Department of Cardiothoracic Surgery, Queen Mary Hospital, Hong Kong. Disclosures: The authors reported no conflicts of interest.

The Journal policy requires editors and reviewers to disclose conflicts of interest and to decline handling or reviewing manuscripts for which they may have a conflict of interest. The editors and reviewers of this article have no conflicts of interest.

Received for publication April 21, 2020; accepted for publication April 21, 2020; available ahead of print May 1, 2020

Address for reprints: Michael K. Y. Hsin, FRCS, CTh, Department of Cardiothoracic Surgery, Queen Mary Hospital, Room 308, New Clinical Building, Hong Kong (E-mail: mkhsin@hotmail.com).

J Thorac Cardiovasc Surg 2021;161:1686-7

$0022-5223 / \$ 36.00$

Copyright (c) 2020 by The American Association for Thoracic Surgery

https://doi.org/10.1016/j.jtcvs.2020.04.079

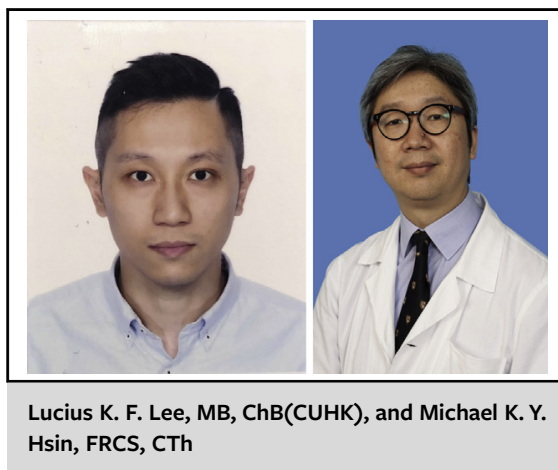

CENTRAL MESSAGE

Cadaveric lobar lung transplant is

often performed for very sick

patients, which is reflected in the

early outcomes. Mid- and

long-term results, however, are

comparable with standard lung

transplant.

Donor-recipient size matching methods include chest radiograph parameters, the ratio of donor and recipient heights, and the ratio of the predicted total lung capacity of the donor and the recipient (pTLC ratio). ${ }^{8}$ In Toronto, nonanatomical downsizing is performed when the donor pTLC is up to $1 \mathrm{~L}$ more than the recipient pTLC, whereas when the donor pTLC exceeds by $1.0 \mathrm{~L}$, they consider LLTx.

Intraoperative circulatory support was mandatory, to reduce reperfusion injury, because of the smaller vascular bed in LLTx. The Toronto group routinely performed a back-table lobectomy. This can be done by a separate surgeon in parallel with the recipient operation, thus reducing the ischemic time, and the view of the hilum is unobstructed. Technically, the dissection is more difficult because the blood vessels are empty. Alternatively, lobectomy can be performed after lung implantation. However, this means operating inside a small chest cavity, and following reperfusion, the lung parenchyma may be more edematous and prone to tearing.

A pooled analysis of 8 studies of LLTx showed an increased relative risk of 1-year mortality of 1.85 compared with standard LTx. ${ }^{8}$ The Toronto results showed the gap between LLTx and standard LTx has decreased, despite a sicker cohort, most probably because of intraoperative extracorporeal membrane oxygenation, implementing ex vivo lung perfusion assessment, and growing experience. In the Toronto series, rapidly deteriorating status was not an 
independent risk factor for mortality. Interestingly, in a series from Leuven, when LLTx was performed on patients with stable cystic fibrosis, no difference in mortality was found between LLTx and standard LTx groups. ${ }^{9}$

Overall, the Toronto experience reaffirms that LLTx is an important option for patients of small stature who would otherwise languish on the waiting list, and recognizing the challenges involved, this should be performed by experienced centers.

\section{References}

1. Aigner C, Winkler G, Jaksch P, Ankersmit J, Marta G, Taghavi S, et al. Size-reduced lung transplantation: an advanced operative strategy to alleviate donor organ shortage. Transplant Proc. 2004;36:2801-5.

2. Bisson A, Bonnette P, el Kadi NB, Leroy M, Colchen A. Bilateral pulmonary lobe transplantation: left lower and right middle and lower lobes. Ann Thorac Surg. 1994;57:219-21.
3. Campo-Cañaveral de la Cruz JL, Dunne B, Lemaitre P, Rackauskas M, Pozniak J, Watanabe Y, et al. Deceased-donor lobar lung transplant: a successful strategy for small sized recipients. J Thorac Cardiovasc Surg. 2021;161:1674-85.

4. Inci I, Benden C, Kestenholz P, Bechir M, Grünenfelder J, Weder W. Long-term outcomes of bilateral lobar lung transplantation. Eur J Cardiothorac Surg. 2013;43:1220-5.

5. Shigemura N, D’Cunha J, Bhama JK, Shiose A, Abou El Ela A, Hackmann A et al. Lobar lung transplantation: a relevant surgical option in the current era of lung allocation score. Ann Thorac Surg. 2013;96:451-6.

6. Mitilian D, Sage E, Puyo P, Bonnette P, Parquin F, Stern M, et al. Techniques and results of lobar lung transplantations. Eur J Cardiothorac Surg. 2014;45:365-9; discussion 369-70.

7. Slama A, Ghanim B, Klikovits T, Scheed A, Hoda MR, Hoetzenecker K, et al Lobar lung transplantation-is it comparable with standard lung transplantation? Transpl Int. 2014;27:909-16.

8. Eberlein M, Reed RM, Chahla M, Bolukbas S, Blevins A, Van Raemdonck D, et al. Lobar lung transplantation from deceased donors: a systematic review. World $J$ Transplant. 2017;7:70-80.

9. Stanzi A, Decaluwe H, Coosemans W, De Leyn P, Nafteux P, Van Veer H, et al Lobar lung transplantation from deceased donors: a valid option for small-sized patients with cystic fibrosis. Transplant Proc. 2014;46:3154-9.
See Article page 1674 .

\section{Commentary: Lobar lung transplantation: Trick or treat-(ment)}

György Lang, MD, PhD, and Walter Klepetko, MD

In the paper "Deceased-Donor Lobar Lung Transplant: A Successful Strategy for Small-Sized Recipients," Campo-Cañaveral de la Cruz and colleagues ${ }^{1}$ report about their institutional experience with lobar lung transplantation (LLTX) and suggest it as a valuable option to overcome especially the scarcity of small donor organs. In fact, although LLTX has been described already for many years, ${ }^{2}$ it has never achieved a wide acceptance by the majority of

\footnotetext{
From the Department of Thoracic Surgery Medical University of Vienna, Vienna, Austria.

Disclosures: The authors reported no conflicts of interest.

The Journal policy requires editors and reviewers to disclose conflicts of interest and to decline handling or reviewing manuscripts for which they may have a conflict of interest. The editors and reviewers of this article have no conflicts of interest.

Received for publication April 22, 2020; accepted for publication April 23, 2020; available ahead of print May 1, 2020.

Address for reprints: Walter Klepetko, MD, Medical University of Vienna, Allgemeines Krankenhaus Wien, Währinger Gürtel 18-20, A-1090 Vienna, Austria (E-mail: walter.klepetko@meduniwien.ac.at).

J Thorac Cardiovasc Surg 2021;161:1687-8

$0022-5223 / \$ 36.00$

Copyright (c) 2020 by The American Association for Thoracic Surgery

https://doi.org/10.1016/j.jtcvs.2020.04.084
}

\section{Check for updates}

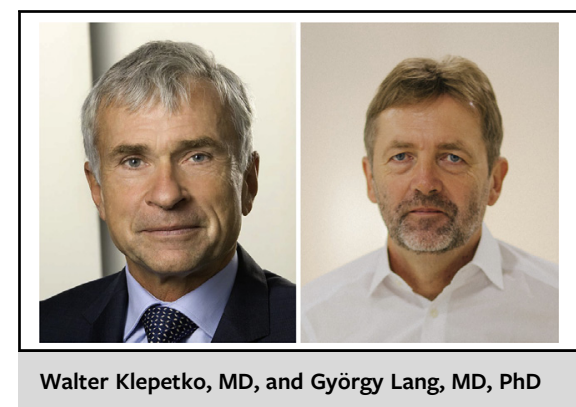

CENTRAL MESSAGE

Deceased LLTX is a valuable tool to expand the possibilities of transplantation and to overcome the scarcity of small donor lungs.

transplant centers. For this reason, the authors of the current article deserve credit for bringing this important topic to our attention.

LLTX is a clearly much more challenging technique, compared with standard "whole" lung transplantation. To safely apply this technique, it requires both considerable 